\title{
Generic Skills in Software Engineering Master Thesis Projects: Towards Rubric-Based Evaluation
}

\author{
Robert Feldt \\ Systems and Software Engineering \\ Blekinge Institute of Technology \\ Ronneby, Sweden \\ rfd@bth.se
}

\author{
Martin Höst \\ Computer Science \\ Lund University \\ Lund, Sweden \\ martin.host@cs.lth.se
}

\author{
Frank Lüders \\ School of Innovation, Design and Engineering \\ Mälardalen University \\ SE-721 23 Vsters, Sweden \\ frank.luders@mdh.se
}

\begin{abstract}
There has been much recent interest in how to help students in higher education develop their generic skills, especially since this is a focus of the Bologna process that aims to standardize European higher education. However, even though the Master thesis is the final and often crucial part of a graduate degree and requires many generic skills very little research has directly focused on them. In particular, there is a lack of such knowledge for engineering education programs. In this paper we present results from a survey where we asked 23 students from three different Swedish universities about which generic skills are needed and developed in a Master thesis project in Software Engineering. One outcome of our analysis is that there is a lack of understanding on how to define, and thus examine, generic skills in software engineering thesis projects.
\end{abstract}

\section{Introduction}

A higher education does not only give the student a specific set of facts, knowledge and skills. It also develops general skills that are useful in a wide set of situations. Development of such generic skills (GS) can be as, or sometimes more, important than the specific subject knowledge from a course.

The European Union has initiated the Bologna process (BP) to standardize its higher education system by 2010 [1]. Different countries within the EU are free to interpret and adapt the BP and its documents to its own educational system, even if the general direction is fixed. Within the Bologna process there is an emphasis on the development of generic skills. Even though general lists of generic skills have been developed no specific prior work has focused on Master thesis projects.

A Master thesis is an intermediate degree between a basic, bachelor degree and an advanced, $\mathrm{PhD}$ degree. It has elements of both research and advanced development and also application of knowledge in industry. In Sweden, a Master thesis project is typically a 20 -week project at the end of a two-year Master programme. In practice, it is quite common that Master thesis projects take more than 20 weeks to actually finish. More information about Master thesis projects can, for example, be found in [2] and [3].

Within the Bologna process very little has been said about the thesis projects. In [4], initial experiences from a Master thesis course improvement project carried out at Blekinge Institute of Technology (BTH) has been described. However, we have not found any empirical investigations into generic skills within Master thesis projects. This paper presents an initial study on how students conducting or having finished their Master thesis projects view generic skills.

The BP itself does not specify how to achieve the goals outlined in its declarations. However, since 2000 the European Commission has funded the Tuning project, in which 130 European universities across 16 countries, have been working to make the goals a reality [5]. The result is a platform for developing reference points at subject area level that makes programmes comparable and compatible. The reference points are expressed 
as learning outcomes, i.e. statements of what a learner is expected to have learnt, or as competences, i.e. the dynamic combination of knowledge, understanding, skills and abilities developed over several courses and years of a study programme [5]. The Tuning framework specifies levels of learning to be achieved at the different educational cycles (Bachelor, Master, Doctor). The reference points can be either generic or subject-specific. Even though subject-specific competences is the basis for university degree programmes, Tuning has highlighted the importance of also developing generic skills that prepare students for their future role in society and increases their employability.

As part of the Tuning project, a large scale consultation was organized involving both graduates, employers and academics. For most competences there was a large similarity between different academic fields. Examples are the capacity for analysis and synthesis, capacity to learn and problem solving. In a similar way, generic competences important for employability was identified. Subject specific competences was identified for nine subject areas. They did not include any computer science or engineering or informatics areas; the ones that were the most similar to these areas were: Chemistry, Mathematics and Physics.

\section{Survey design and administration}

One of the authors created an initial draft of the questions to be used in a questionnaire which the other authors then reviewed and updated slightly. The questionnaire is based on the generic skills listed in the course syllabus for the 'Master Thesis in Software Engineering' (course code: PA2403) given at Blekinge University of Technology $(\mathrm{BTH})$. BTH have recently reworked all course syllabi to fulfill the requirements that the university have interpreted as stated by the Bologna process. One of the sections in this new syllabus template is named 'Generic skills' and calls for the generic skills trained by the course to be listed. All of the generic skills listed in the PA2403 syllabus have been chosen from lists made available by the Tuning project [5]. The choice was rather arbitrary and was done by the examiner: all generic skills that were thought to have a chance of being adressed during a Master thesis project were simply included.

When developing our questionnaire we also added questions to the questionnaire about how well the students thought their previous education had supported their development of generic skills, how important they thought generic skills would be to their future career, and basic questions about the status of their project as well as education in general.

The questionnaire was administered through a web interface via a web service [6]. The link to the questionnaire and a request to participate was sent in an email to both students that had finished and students that were conducting their Master thesis projects. Answer frequencies were generally low (in the range 30-50\% depending on university), especially for students that had already finished their theses.

\section{Results}

Out of the 23 answers, 12 (52.2\%) were from students at BTH, 7 (30.4\%) from Mälardalen University (MdH) and 4 (17.4\%) from Lund University (LU). 17 (73.9\%) had finished their thesis and $6(26.1 \%)$ was still working on it. A majority of studens had started their thesis projects in January 2008 while a few had started in the autumn of 2007. Most had or were finishing their projects during the summer months of 2008. Students had been studying in either Software Engineering or Computer Science programmes. Twelve of the projects were done in academia while eleven were connected to a company.

The Software Engineering areas where the projects had been conducted were reported as: Development and Implementation (30.43\%), Requirements Engineering (30.43\%), Design and Architecture (17.39\%), Verification and Validation (17.39\%), and Tool support (4.35\%).

Table 1 summarizes the answers to questions 10 and 11 that listed the different generic skills. The skills have been ordered based on their average score for the first question. the skills have been ordered based on their average score. The average score was calculated by weighting each answer (very high $=4$, high degree $=3$, small 
Table 1. Questions 'Skills important to finish thesis' and 'Skill improvement during thesis'

\begin{tabular}{|l|c|c|}
\hline Generic skill & Skills important to finish thesis (sorted) & Skill improvement during thesis \\
\hline a, Capacity for analysis and synthesis & 3.39 & 3.13 \\
o, Will to succeed & 3.39 & 3.04 \\
i, Problem solving skills & 3.35 & 2.87 \\
e, Information management skills & 3.26 & 2.95 \\
c, Planning and time management skills & 3.22 & 2.83 \\
d, Research skills & 3.22 & 3.22 \\
p, (Academic) Writing skills & 3.22 & 3.26 \\
h, Capacity for generating new ideas (creativity) & 3.17 & 2.78 \\
n, Concern for quality & 3.13 & 3.04 \\
b, Capacity for applying knowledge in practice & 2.96 & 3.04 \\
l, Ability to work autonomously & 2.96 & 2.57 \\
q, Oral Presentation skills & 2.91 & 2.87 \\
f, Critical and self-critical abilities & 2.83 & 2.65 \\
j, Decision-making skills & 2.83 & 2.43 \\
g, Capacity to adapt to new situations & 2.74 & 2.61 \\
m, Initiative and entrepreneurial spirit & 2.74 & 2.70 \\
k, Interpersonal skills & 2.61 & 2.61 \\
\hline
\end{tabular}

Table 2. Future career and university support (Q. 12)

\begin{tabular}{|l|c|c|c|c|c|}
\hline Question & Very high d. & High d. & Small d. & Very small d. & Av. score \\
\hline are generic skills important to your future career? & 12 & 9 & 2 & 0 & 3.43 \\
have your university supported your development of generic skills? & 3 & 15 & 4 & 1 & 2.87 \\
\hline
\end{tabular}

degree $=2$, very small degree $=1$ ) summing them and dividing by the number of answers. All 23 respondents answered both questions for all generic skills.

Table 2 uses the same calculation for the average score but also states the number of answers in each category for the two questions within question number 12.

Many different suggestions were given by the respondents to the open-ended question number 13 on how the university could better support the development of generic skills. However, not many of them were specific to generic skills: 'Focus more on the skills needed in industry; research skills are too heavy for industry use', 'More courses like the thesis work; earlier courses too focused on specific areas', 'Research part of thesis work not practised enough prior to thesis', 'Academic writing courses early in programme'.

\section{Discussion}

In general it can be seen that general competences are perceived as important by the students when they conduct their Master thesis project. Some of the factors in Table 1 have been given rather high values and no factor has been given a really low value. The mean value of the answering alternatives is $(1+2+3+4) / 4=2.5$ and only for one factor ( 2.43 for factor $\mathrm{k}$ - Interpersonal skills) the mean of the students' answers is lower than the mean.

Even if the students think that the factors are important, there is a difference between the answers for different factors, and some factors have been given higher values than others. These differences are not evident or trivial to explain. For example, the factor " $m$, Initiative and entrepreneurial spirit" has been given a value that is lower than many of the other factors, which means that it is not seen as important by the students as the other factors are. This is not in accordance with the experience that the authors of this paper have from different thesis projects. We believe that the ability to take initiative during a thesis work and thereby to be able to take control of the work is a very important ability during a thesis work, as it is in any other project. Since the aspect of leading other people is not as important in thesis projects as in projects in general, there is less emphasis on management 
skill such related to finance, accounting, organization, motivation etc. as outlined by Project Management Body Of Knowledge (PMBOK) [7]. So the factor $m$ in our investigation is more important than it was perceived by the students during the investigation. We hypothesize that it is the wording of the skill itself (as taken from the Tuning projects documentation) that could be causing this. Since "initiative" here is connected to entrepreneurial spirit, which might give associations more to startups and the building of a company, the association to general initiative and drive might be lost.

The analysis above points to a general problem with the general competences as labeled in the Tuning project. The general competences are hard to interpret and different people may understand the meaning of them differently. This may be one reason why some answers are lower than others, even if no value is really low. Another reason to the dispersion of the answers may be that the students have not thought so much about this before. According to our experience the students, in many cases, are mostly focused on the technical aspects of the thesis project. Since they are students in a technical faculty following an engineering educational program, this may be natural, but the general competences are important too and requested by industry. In our courses we have found that students knows this, and thus might give the factors rather high values even if it would be hard for them to formulate a complete list of general competences. Universities need to be clearer on the importance of generic skills and define and teach them more clearly and throughout the edutcation. At BTH, we have developed a rubrics-based framework for grading theses and thesis projects. We now propose to use rubrics also for definining and examining generic skills in thesis projects.

\section{Conclusions}

We have conducted an survey on the importance of generic competencies to 23 students that are currently finishing or have recently finished their Master thesis project in Software Engineering. Apart from general questions about their educational background and the status of their thesis project the main questions focused on generic competences taken from the EU-funded Tuning project. Based on this study we found that although students have rated a majority of competences as important for their thesis, the relative ordering of the competences was not in line with the expectance of thesis supervisors with extensive experience. We think that a main factor to explain this is that it is not clear to students what different generic competences, as described by the Tuning project, means. We propose that an existing rubrics-based thesis evaluation framework can be extended to also support the definition, clarification and examination of generic skills.

\section{References}

[1] "European Commision's homepage for the Bologna Process," http://ec.europa.eu/education/policies/educ/bologna/ bologna_en.html, July 2008.

[2] M. Höst, B. Regnell, and P. Runeson, Att genomföra examensarbete. Studentitteratur, 2006.

[3] "Homepage for NSHU project PIFF (Supporting framework for Software Engineering diploma work done in collaboration between industry and research in Sweden)," http://www.idt.mdh.se/ gdc/work/PIFF-NSHU.htm, July 2008.

[4] R. Feldt, "Improving a Master Thesis course for Bologna and Industrial and Academic Relevance," in NU 2008, Kalmar, Sweden, May 2008, to appear.

[5] Tuning General Brochure, "Introduction to Tuning," European Union Directorate of Education and Culture, Brussels, Tech. Rep., 2006.

[6] "SurveyGizmo - a web tool for questionnaires and polls," http://www.surveygizmo.com, May 2008.

[7] W. R. Duncan, A Guide to the Project Management Body of Knowledge. Project Management Institute, 1996. 